\title{
Pulmonary toxoplasmoma presenting as obstructive pneumonia
}

\author{
E MONSÓ, R VIDAL, X DE GRACIA, A MORAGAS
}

From the Pneumology Section of the Internal Medicine Department and the Pathology Department, General Hospital Vall d'Hebron, Barcelona, Spain

Human infection by Toxoplasma gondii is very common, judged by the high frequency of toxoplasma antibodies in adult populations. ${ }^{1}$ Lymphadenopathy is the most commonly recognised clinical manifestation. Many cases are probably symptomless. Less frequent but more serious are the encephalitic and disseminated forms, which are usually found in immunosuppressed patients. ${ }^{2}$ With the exception of the central nervous system, toxoplasmosis rarely affects isolated organs, although cases of myocarditis, pericarditis, myositis, and hepatitis have been described. ${ }^{34}$ Isolated pulmonary disease is rare: it presents as pneumonia, usually of the interstitial type. ${ }^{56}$ We describe a healthy adult who presented with localised pulmonary toxoplasmosis, in the form of a mass causing bronchial stenosis and leading to obstructive pneumonia caused by Gram negative organisms. This patient also had many other opportunistic infections.

\section{Case report}

A 49 year old heterosexual man was admitted to our hospital in August 1983 because of fever and weight loss of three months' duration. He admitted to being a smoker and an alcoholic.

The patient's symptoms began in May 1983 with malaise, fever, and cough productive of mucopurulent sputum. An infiltrate in the right upper lobe was detected on the chest radiograph. The packed cell volume was 0.39 and the white blood cell count $8.5 \times 10^{9} / 1$ (80\% neutrophils, $11 \%$ lymphocytes, $7 \%$ monocytes and $2 \%$ band forms). The patient was first treated with multiple antibiotics (penicillin, aminoglycosides, rifampicin) by oral and intramuscular routes for several weeks but without any clinical improvement, and was then admitted to hospital for further investigation.

Examination showed that the patient was febrile $\left(38.2^{\circ} \mathrm{C}\right)$, with hepatosplenomegaly of $2 \mathrm{~cm}$. The chest radiograph demonstrated a cavitated opacity in the right upper lobe (figure). A tuberculin test with 5 units PPD gave a negative result. The packed cell volume was 0.36 and the white blood cell count $2.4 \times 10^{9} / 1$ ( $50 \%$ neutrophils, $23 \%$ lymphocytes, $7 \%$ monocytes, $20 \%$ band forms). Serum aspartate transaminase activity was $121 \mathrm{IU} / \mathrm{ml}$ and alanine transaminase 73 $\mathrm{IU} / \mathrm{ml}$ (normal values $<40 \mathrm{IU} / \mathrm{ml}$ ). The prothrombin time was $64 \%$, IgG concentration 6.1 (normal 8-18) g/l, IgA 0.4 (normal 0.9-4.5) g/1, IgM 0.4 (normal 0.6-2.8) g/l, albumin

Address for reprint requests: Dr Eduard Monsó i Molas, Comtes d'Urgell 29 3er $1^{2}$, Lleida, Spain.

Accepted 29 October 1985
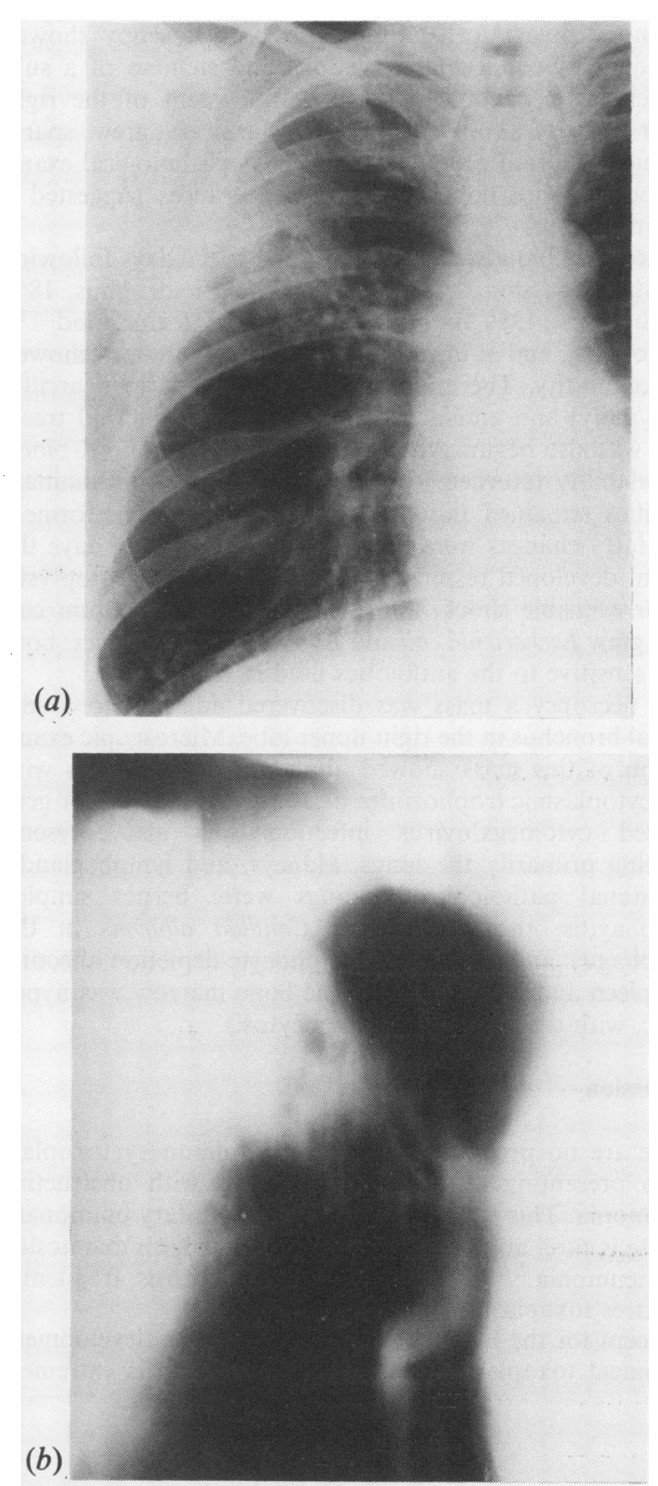

(a) Chest radiograph showing right upper lobe opacity with cavitation; (b) tomographic appearances. 
$27 \mathrm{~g} / \mathrm{l}$, and cholesterol $168 \mathrm{mg} / 100 \mathrm{ml}(4.2 \mathrm{mmol} / \mathrm{l})$. Blood concentrations of urea nitrogen, glucose, calcium, and creatinine were all normal. The urine was normal on microscopy. The following serological tests yielded negative results: rheumatoid arthritis latex test, Brucella agglutination test, Salmonella typhi agglutinins, fluorescent treponemal antibody absorption test (Venereal Disease Reference Laboratory), serum precipitins against Mycoplasma pneumoniae, and hepatitis B surface antigen. The electrocardiogram was normal.

Treatment was begun with clindamycin $(1200 \mathrm{mg} /$ daily $)$ and gentamicin $(240 \mathrm{mg} /$ daily), but no therapeutic response was seen. Examination of sputum revealed no mycobacteria and no neoplasic cells. Fibreoptic bronchoscopy showed abundant mucopurulent secretions and stenosis of a subsegmentary bronchus in the apical segment of the right upper lobe. Culture of bronchial aspirate grew sparse colonies of Gram negative bacilli. Histopathological examination was not conclusive but appearances suggested a benign tumour.

The white blood cell count dropped in the days following hospital admission to $1.6 \times 10^{9} / 1(64 \%$ neutrophils, $18 \%$ lymphocytes, $13 \%$ monocytes, $4 \%$ band forms, and $1 \%$ eosinophils), and at this time a bone marrow biopsy showed rich cellularity. The antibiotics were changed to ticarcillin $(20 \mathrm{~g} /$ daily $)$ and amikacin $(1 \mathrm{~g} /$ daily); corticosteroid treatment was also begun. After treatment with vitamin $\mathrm{K}$ blood coagulability returned to normal, but serum transaminase activities remained raised. A liver biopsy was performed; only fatty changes were present. In the following days the patient developed respiratory failure, massive haemoptysis, and irreversible shock, and died. Subsequent sputum cultures grew Escherichia coli and Enterobacter aerogenes; both were sensitive to the antibiotics used in treatment.

At necropsy a mass was discovered adjacent to a segmental bronchus in the right upper lobe. Microscopic examination of this mass showed abundant macrophages with intracytoplasmic trophozoites of Toxoplasma gondii. A generalised cytomegalovirus infection was also present, affecting primarily the lungs, kidneys, and lymph glands. Additional pathological findings were: herpes simplex oesophagitis, the presence of Candida albicans in the oesophagus, and substantial lymphocyte depletion affecting the spleen and lymph glands. The bone marrow was hypoplasic, with signs of erythrophagocytosis.

\section{Discussion}

There are no previous references to pulmonary toxoplasmosis presenting as a pulmonary mass with obstructive pneumonia. This is presumably because solitary pulmonary disease is rare, and in recorded cases it has been manifested as pneumonia. ${ }^{56}$ Disseminated toxoplasmosis frequently produces toxoplasmal pneumonia $(72.9 \%){ }^{2}$

Except for the lymphadenopathic form, the development of clinical toxoplasmosis in a healthy person is extremely of clinical toxoplasmosis in a healthy person is extremely rare. ${ }^{246}$ In contrast, severe toxoplasmal infections are frequent in immunosuppressed patients and are usually associated with opportunistic microorganisms. ${ }^{34}$ The discovery of toxoplasma pseudocysts, however, cannot be taken as a confirmation of active infection as these forms may remain in tissues for long periods after a benign infection..$^{34} 78$ The diagnosis of active toxoplasmosis requires the demonstration of trophozoites in the tissues.

The fact that we found other opportunistic infections in this patient (cytomegalovirus, herpes, candida) led us to suspect the existence of immunodeficiency. Humoral immunity appeared to be acceptably preserved throughout the disease process. Unfortunately we could not confirm the existence of a cellular immunity deficit, although the tuberculin anergy $\sigma$ and lymphopenia would suggest this. In the last weeks of the disease the patient developed neutropenia, which probably provoked an acceleration of the final clinical picture. It is 윽 well known that cytomegalovirus is capable of depressing cellular immunity. ${ }^{9}$ On the other hand, cellular immunity is of fundamental importance for an adequate defence against Toxoplasma gondii, an intracellular protozoon. ${ }^{48}$

Interestingly, the course of this patient's disease coincided in many respects with that of cases described since 1981 as acquired immune deficiency syndrome (AIDS), ${ }^{10}$ in which healthy adults develop diverse opportunistic infections. The coexistence of lymphopenia would be compatible with this diagnosis, but none of the risk factors for AIDS was known to be present in our patient.

\section{References}

1 Krick JA, Remington JS. Toxoplasmosis in the adult. An overview. $N$ Engl J Med 1978;298:550-3.

2 Yermakov V, Rashid RK, Vuletin JC, Pertschuk LP, Isaksson H. Disseminated toxoplasmosis. Arch Pathol Lab Med 1982;106: 524-8.

3 Ruskin J, Remington JS. Toxoplasmosis in the compromised host. Ann Intern Med 1976;84:193-9.

4 Ryning FW, Mills J. Pneumocystis carinii, Toxoplasma gondii, cytomegalovirus and the compromised host. West J Med $\mathrm{O}$ 1979;130:18-34.

5 Ludlam GB, Beattie CB. Pulmonary toxoplasmosis. Lancet 1963;ii:1136-8.

6 Niutta R, Fatigante R. Miliare polmonale de Toxoplasma gondii in adulto. Minerva Med 1979;130:18-34.

7 Peacock JE, Folds J, Orringer E, Luft B, Cohen MS. Toxoplasma N gondii and the compromised host. Arch Intern Med 1983;143:1235-7.

8 Scott RJ. Toxoplasmosis. Trop Dis Bull 1978;75:809-27.

9 Rinaldo CR, Carney WP, Richter BS, Black PH, Hirsch MS. Mechanisms of immunosuppression in cytomegaloviral mononucleosis. J Infect Dis 1980;141:488-95.

10 Centers for Disease Control. Update on acquired immunodefiency syndrome (AIDS). US Morbid Mortal Weekly Rep 1982;31:507-14. 